FEYERABEND, Paul K. Ciência, um Monstro: lições trentinas.

\author{
Tradução de Rogério Bettoni.
}

Belo Horizonte: Autêntica, 2016.

\title{
Desarmonia: uma virtude da ciência
}

\author{
Doutoranda \\ Francine Marcondes Castro Oliveira \\ Universidade Estadual de Maringá \\ fran.ufpr@gmail.com \\ Recebido em 11/02/17 \\ Aceito em 13/02/17 \\ Para citar este artigo: OLIVEIRA, \\ Francine Marcondes Castro. \\ Resenha do livro FEYERABEND, Paul K. \\ Ciência, um Monstro: lições trentinas. \\ Em Construção. ano 1, \\ n. 1, 2017, pp. 157-164. DOI:10.12957/ \\ emconstrucao.2017.28130
}

O último livro de Paul Feyerabend constitui a transcrição de quatro conferências e um debate ocorridos entre 4 e 8 de maio de 1992 na Universidade de Trento (Itália). O fio condutor das explanações do pensador austríaco foi a natureza não harmônica da ciência, que é contrastante com a imagem de "todo coerente" que geralmente é atribuída a esse empreendimento.

O contexto das conferências foi controverso. Apesar de o evento ter sido organizado com o único intuito de possibilitar a discussão de temáticas ligadas à teoria feyerabendiana - e que, assim sendo, possa ter tido uma atmosfera honrosa -, é possível imaginar que a presença de Feyerabend em Trento no ano de 1992 tenha rendido algumas "saias justas" ao autor.

Pouco mais de dois anos tinham se passado desde que o Cardeal Ratzinger utilizara uma citação de Contra o método para corroborar sua justificação pública da atitude da igreja católica em relação a Galileu Galilei no século XVII. Para completar, em entrevista ao jornalista Marcello Frediani - do jornal independente Il Sabato (12 de maio de 1990) - Feyerabend (sendo Feyerabend) declarou: "Minha posição foi corretamente apresentada [pelo Cardeal Ratzinger]" (FEYERABEND, 2016, p. 15). Tais ocorrências levaram parte significativa da comunidade científica italiana a incluir o austríaco na lista de "ameaças à autonomia da ciência" e de torná-lo foco de um fervoroso movimento de rejeição que ainda não havia esfriado em 1992.

A leitura do fragmento utilizado por Ratzinger, entretanto, pode render discussões com outros sentidos. Nele Feyerabend afirma: 
A Igreja, na época de Galileu, não apenas conservou-se mais próxima à razão tal como esta era definida então e, em parte, mesmo hoje: também considerou as conseqüências éticas e sociais das idéias de Galileu. Sua indiciação de Galileu foi racional, e somente oportunismo e falta de perspectiva podem exigir uma revisão (FEYERABEND, 2007, p. 181).

A adesão de Ratzinger às ideias feyerabendianas, bem como o choque da comunidade científica estão provavelmente apoiados na noção de Racionalidade (com " $R$ " maiúsculo) compartilhada socialmente (e à qual se apegaram tanto o cardeal como aqueles professores universitários). Essa noção implica a definição da Racionalidade como critério supremo e universal para o julgamento do conhecimento. Portanto, o uso da palavra no referido fragmento funcionaria como um elogio incontestável à igreja e à sua atitude.

Ocorre que essa noção não é ratificada por Feyerabend. O entendimento de que exista uma Racionalidade (com "R" maiúsculo) nem mesmo é visto como razoável pelo autor. Talvez se possa dizer que a racionalidade, na obra feyerabendiana, é contextual, podendo expressar a natureza de qualquer complexo ideário que atribua sentido às elaborações (teóricas e práticas) de uma cosmologia ou visão de mundo.

Como a igreja dominava a cosmologia hegemônica - e que amparava as relações sociais na época -, um julgamento sob seus critérios estaria endossado pela racionalidade daquele contexto. A consideração de que a indiciação teria sido racional, portanto, faz parte do que Hoyningen-Huene e Oberheim (2012, p. 92) definem como "crítica imanente" na obra de Feyerabend. A estratégia argumentativa faz notar que a supremacia de uma tradição é fonte de problemas. Com a ciência predominando sobre todas as demais tradições nos últimos séculos, a situação não é diferente - esta é a questão-chave para Feyerabend.

Mas mesmo com a explícita figuração desse conjunto de ideias em toda sua obra - e notadamente em Contra o método - parece que Feyerabend teve que lidar com ânimos exaltados durante as conferências trentinas. Seja por esta ou outra razão, ele se encontra mais contido do que de costume, sobretudo nas páginas iniciais desta obra.

As quatro conferências e o debate não receberam títulos específicos. A definição do título da obra completa, por sua vez, foi polêmica. Feyerabend se referia aos manuscritos como Conflict and harmony, mas este foi considerado um título ambíguo pelos editoriais do mundo afora - apenas a versão alemã procurou uma aproximação (Winderstreit und harmonie). No Brasil, a escolha de Ciência, um monstro consumou-se como uma tentativa de escapar da polissemia e, ao mesmo tempo, funcionar como um prenúncio do conteúdo dos textos. Erraram o alvo. O título eleito, estampado no contexto da capa (em que figuram vários seres extraordinários), faz o leitor acostumado a Feyerabend experimentar um combo de indefinição com adicional de anfibologia: estaria o autor indicando o potencial nefasto da ciência? Estaria falando da complexidade (monstruosa) da prática científica? Será que Feyerabend trataria de como a tradição científica (como um monstro) engoliu as demais tradições após se tornar hegemônica? Ou Feyerabend estaria confirmando a unidade científica, sob a personificação de um ser multifacetado?

Logo na primeira conferência a questão começa a ser dissolvida à la Feyerabend: o leitor visita Xenófanes e sua ideia de divindade única (um monstro não antropomórfico que pode ajudar a compreender a ideia construída sobre o empreendimento científico). Compreende-se, então, que as hipóteses sugeridas pelo título eram insuficientes/incorretas e que Feyerabend seria mais uma vez surpreendente em sua condução. O grato reencontro com o estilo do autor não alivia o desacerto editorial. Conflito e harmonia possivelmente expressaria melhor o que guarda esta obra ${ }^{1}$.

Mas a primeira conferência, realizada em 4 de maio de 1992 (p. 41-62), não vai direto a Xenófanes. Feyerabend a inicia contrapondo dois acontecimentos públicos daquele ano. O primeiro, conduzido por astrofísicos, referia-se à detecção de variações (já esperadas) em um ruído cósmico, por meio de um satélite especialmente desenvolvido para esse fim. Um acontecimento que corroboraria a teoria do big bang e foi acompanhado com

1 Em sua versão em língua inglesa, o livro recebeu o título The tyranny of science, e cada conferência ganhou um título: 1) Conflict and harmony; 2) The disunity of science; 3) The abundance of nature; e 4) Dehumanizing humans. 
profundo entusiasmo por pessoas do mundo inteiro. O segundo, de natureza trágica, dizia respeito a uma revolta ocorrida em função do resultado de um julgamento segundo o qual policiais que haviam detido e espancado até a morte um motorista negro, em Los Angeles, estavam "apenas fazendo seus trabalhos". Com a revolta, milhares de pessoas ficaram feridas em várias cidades dos Estados Unidos. Apenas em Los Angeles, 42 morreram.

A questão que Feyerabend dirige ao leitor após apresentar os dois acontecimentos vem para perturbar: como relacionar as duas ocorrências? Elas têm relação, ou temos que aceitar que o mundo é uma composição desarmônica, condenada pela sincronia à impossibilidade de compreensão global?

Não é intenção do autor fornecer uma resposta. O leitor precisa respirar fundo e prosseguir. O problema é que as questões apresentadas em seguida não são mais simples.

Feyerabend usa como ensejo uma citação do Prêmio Nobel Jacques Monod para iniciar uma discussão sobre os impactos da ciência na vida das pessoas (FEYERABEND, 2016, p. 44):

A ideia fria e austera, que não propõe nenhuma explicação, mas impõe uma renúncia ascética a qualquer outro alimento espiritual [a ideia de que o conhecimento objetivo é a única fonte autêntica de verdade], não podia acalmar a angústia inata. Ao contrário, a exasperava. Ela pretendia com um só golpe, extirpar uma tradição cem vezes milenar, assimilada à própria natureza humana. Denunciava a antiga aliança animista entre o homem e a natureza, deixando no lugar desse vínculo preciso apenas uma busca ansiosa num universo gélido de solidão. Como uma tal ideia, que parecia não ter a seu favor senão uma puritana arrogância, podia ser aceita? Ela não o foi; ainda não o é. E, se apesar de tudo se impõe, é em virtude unicamente de sua prodigiosa capacidade de produzir resultados.

Provavelmente produzida sem nenhuma referência a Monod, uma cena de um filme recente agrega sentido à discussão suscitada pelas palavras do autor. Essa cena, incluída no início do filme $X$-Men: primeira classe (2011), mostra o vilão Sebastian Shaw - um oficial nazista - tentando persuadir o pré-adolescente Erik Lenhsherr (Magneto) a demonstrar seus poderes mutantes, movendo uma moeda à distância. Erik, que ao ser separado dos pais no campo de concentração, havia contorcido um robusto portão de metal, tenta atender o oficial, sem sucesso. Shaw, procurando um estímulo mais eficaz, decide trazer a mãe do menino à sala e ameaça matá-la caso a moeda não seja movida. Antes disso, porém, Shaw afirma: "A única coisa que sei dos nazistas é que seus métodos dão resultados". A mãe de Erik é trazida à sala e - como isso não é suficiente para que ele mova a moeda -ela é morta em sua presença. A fúria libera os poderes do menino, para a admiração de Shaw.

A apresentação de Feyerabend nos remete ao filme, porque o problema de se avaliar o sucesso de um empreendimento apenas em função de seus resultados é tão aparente na cena descrita quanto em sua abordagem. Para o autor, uma questão essencial sobre a ciência (já expressa em várias obras) é: qual é sua capacidade de promover uma vida mais feliz para as pessoas? Obviamente o sucesso da ciência nesse quesito está sendo questionado. Mas Feyerabend não vai direto ao ponto. Ele simula um vagar. Abduz o leitor para o exercício de resolução do problema contido no fato de que a ciência não apenas não nos forneceu propósitos para a existência, como destruiu os que tínhamos.

A estratégia de argumentação proposta envolve examinar possíveis conexões da ciência com a religião, as artes e a filosofia, na tentativa de desatar nós a partir da colaboração. O resultado é perceber que todos esses empreendimentos compartilham características semelhantes, notadamente, a desarmonia. Mas isso não é um problema para Feyerabend (apesar de contrariar uma persistente expectativa de grande parte da humanidade). Para ele "lastimar sobre uma 'falta de harmonia' significa condenar arranjos que se formaram durante milênios" (FEYERABEND, 2016, p. 47). Daí, constituir uma descrição coerente do mundo nos moldes, por exemplo, de Platão é viável? E desejável?

Feyerabend propõe percorrer esse problema abordando histórias. Sarcasticamente, ele afirma que usará o recurso tal qual o fazem os "verdadeiros especialistas", com a diferença de que estes abordam fábulas mais complicadas. Temperinhos feyerabendianos. 
Ele retrocede a Homero, à educação do homem grego e à presença viva dos deuses em suas atividades cotidianas. A relação desses elementos no mundo antigo parece se conciliar bem com a diversidade e a desarmonia. Há contraste, entretanto, quando o foco muda para o papel dos filósofos. A ideia de Tales de Mileto de encontrar um ponto de unidade entre tudo que compõe o mundo (a água) converge muito mais com a busca de coerência da modernidade. Nas palavras de Feyerabend: "Fazendo suposições como essas, Tales antecipou um princípio básico da ciência moderna - de que existe uma unidade subjacente à variedade de aparências" (FEYERABEND, 2016, p. 53).

Xenófanes é mais um contribuinte da construção desse princípio (e um dos elementos da fala de Feyerabend que dão sentido ao título escolhido na tradução brasileira). Tal filósofo anuncia um ser divino único, que é puro pensamento e que tudo move sem se mover. Para o austríaco, trata-se de um ser muito desinteressante: ele é um alienígena, um monstro inumano, porém possui características humanas, como o pensamento. Sua desconexão com a vida e com as pessoas pode ser o prenúncio da angústia e da solidão relatadas por Monod. Feyerabend questiona se esses filósofos deram impulso a essa onda ou foram sendo levados. Além disso, envereda na discussão sobre como a vida das pessoas comuns foi sendo influenciada por tais concepções.

Se a tradicional causticidade feyerabendiana não pôde ser sentida inteiramente nessa primeira conferência, pelo menos - e como é familiar ao leitor de Feyerabend - pôde-se ver tudo "ser jogado no ventilador" sem maiores preocupações. Dúvidas de altíssimo nível é o que se compartilhou até aqui. Um bom começo.

A segunda conferência, proferida em 5 de maio de 1992 (FEYERABEND, 2016, p. 63-85), inicia-se com a retomada do conteúdo da citação de Monod e, com ele, da lembrança do infortúnio causado em função de a ciência ter jogado a humanidade em um mundo gélido e solitário em troca de resultados.

Quem aceitou isso? Como foi o processo? A adesão foi consciente ou as pessoas foram sendo tomadas paulatinamente por ideias que reconstruíram suas relações com o universo? E, o mais importante: temos como voltar atrás?

$\mathrm{Na}$ avaliação de Feyerabend, a relação entre o custo e o benefício do materialismo científico não foi vantajosa para as pessoas comuns. Em suas palavras, "[...] devemos ficar atentos a tudo que demonstre uma 'prodigiosa capacidade de produzir resultados [...]" (FEYERABEND, 2016, p. 64), e "[...] se isso é tudo que o materialismo científico tem a oferecer, podemos afirmar que estamos interessados em questões muito mais urgentes". (FEYERABEND, 2016, p. 65).

De forma geral, a exposição feyerabendiana na metade inicial da segunda conferência é multidirecional e nada sistematizada (como ele mesmo prometeu). Entretanto, sua abordagem pode ser resumida, segundo suas próprias palavras, em quatro proposições:

Primeira proposição: O progresso da ciência (no sentido de seus defensores) depende de uma abertura das visões de mundo que se contrapõe às afirmações totalitárias de muitos de seus defensores.

Segunda proposição: é preciso muito tempo, às vezes até séculos, para que as visões de mundo mostrem resultados que "se impõem".

Terceira proposição: o que "se impõe" numa comunidade costuma não gerar interesse e às vezes pode ser prejudicial em outra.

Quarta proposição: Uma visão de mundo que contradiga "resultados bem-estabelecidos" pode conflitar com uma tendência ou uma mania religiosa temporária. No entanto, ela não conflita com a mania que todos os cientistas e amantes da ciência abraçam, a saber, $o$ racionalismo (FEYERABEND, 2016, p. 73). 
Os argumentos envolvidos na explanação dessas proposições foram coloridos por críticas aos elementos ilusórios que sustentam a credibilidade da ciência (como a experiência e a tecnicalidade) e por respaldos à liberdade do sujeito comum que, por exemplo, não é obrigado a aderir à ideologia de fundo da ciência só porque desfruta de alguns de seus resultados.

O prosseguimento da exposição envolveu mostrar as garras para a big science e sua desconexão com o mundo real. Feyerabend oferece crítica ao fato de que um rio de dinheiro é despejado sobre empreendimentos como o Projeto Genoma Humano e enaltece o conhecimento local, como a opção mais útil e segura para as pessoas.

O mais intrigante, contudo, foi que, no decorrer da conferência, Feyerabend trouxe à tona a discussão sobre a relação entre a igreja católica e Galileu na época de sua condenação e constituiu todos os passos de uma boa explanação didática (envolvendo inclusive o esclarecimento sobre como uma teoria muito problemática pode produzir resultados). O ensejo para isso é, no mínimo, curioso. Fazer exposição didática de crítica imanente equivale a "explicar a piada". Encontramos Feyerabend em situação semelhante em Ciência em uma sociedade livre (2011) ao responder a críticos que fizeram leituras enviesadas de sua obra. Mais um indício de que as conferências trentinas envolveram "saias justas".

A conferência termina com mais um elemento relacionado ao título da edição brasileira. Feyerabend discute a força da ciência e sua capacidade de colocar até o papa em situação de submissão. O poder dela, entretanto, provém do fato de as pessoas acreditarem em suas promessas e em sua imagem coesa: "quem diz que é a ciência que determina a natureza da realidade presume que as ciências têm uma única voz. Acredita que existe um monstro, a CIÊNCIA, e que quando ele fala, repete e repete sem parar uma única mensagem coerente" (FEYERABEND, 2016, p. 85). Mas este monstro, a ciência, está na mesma classe do bicho papão e poderia animar apenas o universo infantil de hipóteses sobre o mundo.

Na terceira conferência, de 6 de maio de 1992 (FEYERABEND, 2016, p. 87-105), Feyerabend inicia os trabalhos explanando sobre a desproporção entre o prestígio atribuído aos cientistas teóricos e experimentais. Não há nada que possa objetivamente indicar que um desses grupos esteja mais próximo da realidade que o outro. Entretanto, a ideia de que a teoria possui a faculdade de preceder e dar sentido ao experimento, além de integrá-lo em um corpo coerente de conhecimentos, tem subjugado as produções - mais visuais e práticas - dos experimentalistas. Feyerabend lembra que a influência de Platão sobre a cultura hegemônica no Ocidente pode ter tido impactos sobre essa atitude. Em A República, o filósofo encoraja uma digressão quando indica que os domínios práticos são úteis, porém apenas os teóricos contêm conhecimento. Essa ideia teve ressonância ao longo da tradição racionalista - que é muito eficiente em ações publicitárias. Entretanto, o exame mais detido revela tão-somente o quanto novos cientistas estão apegados a velhos preconceitos.

Contraditoriamente, o chamado "sucesso científico" está fortemente ancorado no pressuposto de que a ciência se baseia na observação e no experimento. Uma conjectura enganosa, já que "princípios científicos importantes [inclusive princípios fundamentais, que serviram de pano de fundo para a edificação de áreas inteiras] foram introduzidos em contraposição à experiência [...], não em conformidade com ela" (FEYERABEND, 2016, p. 91, grifos do autor).

A despeito disso, quando a ciência entra em disputa com qualquer outra tradição, o que efetivamente conta não é o que a ciência é, mas o que as pessoas (que decidem) pensam sobre ela - e isso pode incluir proposições auto-excludentes, dada a complexidade das relações estabelecidas entre as fontes de informação.

O fato é que o discurso que desautoriza o conhecimento das pessoas comuns e sustenta a legitimação de alguma espécie de conhecimento especial - sobre-humano - vem sendo cultivado há milênios. Feyerabend recorre a um poema de Czeslaw Milosz, prêmio Nobel de Literatura no ano de 1980, para ilustrar o "quão longe" se pode chegar nesse quesito.

No poema intitulado Conjuro, Milosz consagra a razão humana e a filosofia, atribuindo-lhes qualidades como beleza, invencibilidade e perenidade. Supõe a existência de adversários a essas duas entidades fantásticas 
e anuncia suas inevitáveis vitórias. Por sorte, o leitor é salvo pela lucidez feyerabendiana: "é impressionante ver quanta bobagem pode ser colocada num único poema [...]" (FEYERABEND, 2016, p. 97).

Apesar de Xenófanes, por exemplo, ter trabalhado sob tendência semelhante (e de ter sido um dos precursores dessa tendência), "ele não era tão ruim assim" (FEYERABEND, 2016, p. 97). Em um de seus poemas (também mencionado por Feyerabend) pode-se compartilhar a ambientação de um vívido dia de festa, no qual pessoas reais podem conversar e expressar suas memórias. Também é um poema sobre conhecimento e sabedoria, mas não tão desumanizado quanto o do prêmio Nobel.

O resgate da humanidade em figuras análogas ao cientista na antiguidade conduz Feyerabend a examinar o caso de Pitágoras. Esse pensador fez "contribuições para a aritmética, a geometria, a astronomia e a ética" (FEYERABEND, 2016, p. 99); uniu as capacidades de organizar e manter integrado um grande conjunto de pesquisadores; esteve envolvido na política e fundou seu próprio partido; estabeleceu uma escola (com rígidos critérios de admissão) e a fez crescer por meio de campanhas de publicidade didática.

O que Feyerabend destaca, contudo, é que o conhecimento para Pitágoras não estava apartado da vida. Ele ensinava "como uma maneira de purificação e salvação" (FEYERABEND, 2016, p. 101). A falta de propósito não era uma bandeira ostentada a meio mastro para lembrar a humanidade de sua solidão no universo. A relação estabelecida com o conhecimento podia ter, portanto, uma natureza muito mais abrangente.

A explanação sobre Pitágoras se estende por quase sete páginas e é bastante detalhada. Um aspecto importante dela é a demonstração feyerabendiana de como um dos pressupostos centrais da escola pitagórica - o de que número é a unidade fundamental do universo - se modificou e se converteu em uma tautologia pela própria inflexão da matemática.

A quarta conferência, proferida em 7 de maio de 1992 (FEYERABEND, 2016, p. 107-126) é especialmente densa. Seu eixo é constituído pela análise de como as diversas fontes de influência das atuais racionalidades hegemônicas convergiram para que elas promovessem a desantropomorfização dos seres humanos. O método eleito para a exposição, entretanto, foi o do passeio por narrativas, o que ramifica as possibilidades de insights no decurso da leitura.

Feyerabend recobra sua crítica a Monod e procura examinar como o materialismo pôde se salvar de uma sistemática rejeição quando não representava qualquer coisa para a humanidade, além de uma fecunda fonte de infortúnios. O segredo foi, provavelmente, a sutileza.

Os pressupostos da versão de mundo materialista são provenientes de várias nascentes. Cada qual guiada por uma tendência específica, com profundo sentido contextual. A maior parte desses pressupostos não são nem praticáveis. Sobrevivem como fetiches ou lendas em relação aos quais se desenvolveu profundo apego e confiança. Para enumerar alguns deles, pode-se citar a rejeição a juízos de valor, a objetividade, a necessidade de sistematização e de expressão por meio de uma linguagem estrita (no caso, uma manifestação particular da lógica). Feyerabend transita entre histórias provindas da antiguidade e faz notar como muitas dessas propensões foram germinando independentemente de maneira despretensiosa.

Entrementes, o que o autor destaca é o papel do conhecimento tácito em conjunto com a inevitabilidade do desejável pluralismo.

Se os representantes das práticas estabelecidas evocam o sucesso promovido por elas como justificativa para a sobreposição de seus interesses sobre os de todas as demais tradições, Feyerabend questiona: "Sucesso em quê? Em trazer a paz ou tornar as pessoas mais amáveis?” (FEYERABEND, 2016, p. 110). Notadamente, frente à desumanização, a obra feyerabendiana é um ato de resistência.

O capítulo intitulado Dibattito (FEYERABEND, 2016, p. 127-161) certamente fará feyerabendianos vibrar. Produzido no formato de perguntas e respostas sucintas, o texto tem espaço para o tratamento de muitas temáticas. Nele, por exemplo, Feyerabend oferece uma explicação para o subtítulo de Contra o método (Esboço de uma teoria anárquica do conhecimento) - o que merece ser resguardado de spoilers. Ademais, lê-se Grazia fazendo relato de suas próprias vivências profissionais em apoio às teses do marido: "Trabalhei 
com física durante algum tempo e posso dizer que nada do que eu fazia estava aberto a modificar as leis" (FEYERABEND, 2016, p. 134).

Além disso, algumas das teses tratadas durante as demais conferências foram retomadas ou para serem esclarecidas, ou porque suscitaram comentários críticos entre os intelectuais presentes. Uma explicação particularmente interessante e emblemática diz respeito ao impacto que teve a descoberta de que a raiz quadrada de 2 é um número irracional sobre os geômetras pitagóricos e, posteriormente, sobre a sociedade grega (FEYERABEND, 2016, p.139) - fonte de onde Feyerabend e Kuhn extraíram a metáfora da incomensurabilidade (ABRAHÃO, 2012, p. 21).

Vinte e uma páginas de notas estão incluídas na parte final de Ciência, um monstro. Elas envolvem comentários explicativos dos editores sobre falas de Feyerabend, além de apresentarem referências e transcrições de trechos de obras às quais ele se refere durante as conferências. O próprio Feyerabend não incluiu qualquer nota nos seus manuscritos. Algumas delas foram traduzidas da versão italiana, mas a maioria das notas dessa edição é original.

Também são originais os dois apêndices que sucedem as notas. Ambos prestam um excelente serviço aos estudiosos de Feyerabend. O primeiro constitui uma coletânea de depoimentos pessoais de $\operatorname{cinco}^{2}$ pesquisadores italianos que assistiram às conferências trentinas. São relatos vivos com alguns detalhes surpreendentes. Parte desses relatos diz respeito à imagem de Feyerabend e ao seu modo de exposição nas conferências, mas em geral eles incluem vivências desses pesquisadores em situações diversas envolvendo Feyerabend. Entre esses textos encontram-se afirmações como: "[...] um físico teórico, que hoje é um dos meus melhores amigos, excluiu-me dos agradecimentos quando soube que eu havia escrito sobre Feyerabend (mas depois se desculpou)" (FEYERABEND, 2016, p. 206); "Recordo-me [...] que Feyerabend discorreu sem fazer uso de qualquer texto escrito. [...] Isso me surpreendeu, pois durante suas lições ele citou de memória (ou melhor, declamou) inúmeras passagens dos antigos filósofos e escritores gregos" (FEYERABEND, 2016, p. 209).

No Apêndice II, os editores pretendem apresentar um relatório geral da obra feyerabendiana (o corpus do autor) com base no arquivo online administrado por Matteo Collodel ${ }^{3}$. Nele, os escritos de Feyerabend são agrupados nas categorias (A) Artigos e ensaios - "Epistemologia e Filosofia da ciência"; "Estrutura da ciência e da metodologia científica"; "Crítica da tecnocracia e defesa da democratização da ciência"; "Relação entre ciência e arte"; "Realismo"; "Origem do Racionalismo e da tradição teórica/abstrata" e "Filosofia da teoria quântica"; (B) Livros e coletâneas; (C) Cartas e entrevistas; (D) Feyerabend em português (incluindo até mesmo os sumários das obras); e (E) Estudos complementares - "Livros"; "Coletâneas de textos"; "Artigos e ensaios"; e "Feyerabend no Brasil".

Na última subcategoria - "Feyerabend no Brasil" - o editor passa longe de constituir uma listagem significativa das produções nacionais sobre o autor. Dezessete obras são relacionadas, envolvendo seis artigos, oito livros, uma dissertação e duas teses. Entretanto, apenas no Banco de Teses e Dissertações da Capes, há dezenove trabalhos que fazem menção a Feyerabend no título, e isso, evidentemente, é só um fragmento da produção existente.

Não obstante, o saldo final indica que a edição brasileira foi muito bem organizada. Além do conteúdo extra, apresenta uma cuidadosa tradução - de Rogério Bettoni ${ }^{4}$ - e textos de apresentação que fazem jus à obra - uma amostra da indiscutível contribuição que Luiz Henrique de Lacerda Abrahão tem prestado à divulgação do pensamento feyerabendiano no Brasil. Entre os trabalhos mais recentes do autor, destaca-se, por exemplo, a organização da obra Kuhn, Feyerabend e incomensurabilidade: textos selecionados de Paul Hoyningen-Huene (ABRAHÃO, 2012).

2 Os pesquisadores que compuseram os relatos desses apêndices foram: "o historiador da ciência Renato Mazzolini, o psicanalista Sergio Benvenuto, o jurista Ugo Mattei e os sociólogos Massiami Bucci e Riccardo Scartezzini” (p. 187). Os testemunhos prestados exclusivamente para a edição brasileira ocorreram mais de duas décadas depois das conferências trentinas.

3 O endereço do arquivo de obras feyerabendianas administrado e periodicamente atualizado por Matteo Collodel é: http:// www.collodel.org/feyerabend/.

4 Com exceção do Apêndice I, que contou com a parceria de Alessandro Baungartner. 
Ciência, um monstro é, portanto, altamente recomendável. Não é uma obra finalista, mas extrato de Feyerabend na veia. As familiares teses do autor estão presentes, sem contradições ou inovações, mas não da maneira convencional. Elas são entrelaçadas em narrativas densas, como os arquétipos que compunham a sabedoria das antigas tradições. É uma obra intensa, para ler muitas vezes. Essencial não apenas para os estudiosos de Feyerabend como também para qualquer interessado em discutir a ciência e sua natureza (não harmônica).

\section{Referências bibliográficas}

ABRAHÃO, Luiz Henrique de Lacerda (Org.). Kuhn, Feyerabend e incomensurabilidade: textos selecionados de Paul Hoyningen-Huene. Tradução de Luiz Henrique de Lacerda Abrahão. São Leopoldo, RS: Unisinos, 2012.

FEYERABEND, Paul. Contra o método. 3. ed. Tradução de Cezar Augusto Mortari.São Paulo:Editora UNESP, 2007.

. Ciência em uma sociedade livre. Tradução de Vera Joscelyne.São Paulo: UNESP, 2011.

HOYNINGEN-HUENE, Paul; OBERHEIM, Eric. Novidades sobre Feyerabend. In: ABRAHÃO, Luiz Henrique de Lacerda (Org.). Kuhn, Feyerabend e incomensurabilidade: textos selecionados de Paul Hoyningen-Huene. Tradução de Luiz Henrique de Lacerda Abrahão.São Leopoldo, RS: Unisinos, 2012.

X-MEN: Primeira Classe. Direção: Matthew Vaughan. Produção: Lauren Shuler Donner et al. New York City, NY: Marvel Entertainment, 2011. 1 DVD (132 min). 